Check for updates

Cite this: Chem. Sci., 2019, 10, 4322

๑ All publication charges for this article have been paid for by the Royal Society of Chemistry

Received 5th December 2018

Accepted 12th March 2019

DOI: $10.1039 / c 8 s c 05439 h$

rsc.li/chemical-science

\title{
Access to P-chiral phosphine oxides by enantioselective allylic alkylation of bisphenols $\uparrow$
}

\author{
Guo-Hui Yang, Yao Li, Xin Li (iD)* and Jin-Pei Cheng \\ A novel biscinchona alkaloid-catalyzed highly enantioselective desymmetrization reaction of \\ bisphenol compounds with achiral Morita-Baylis-Hillman carbonate agents was developed. \\ Through the asymmetric allylic alkylation strategy, a broad range of optically active P-stereogenic \\ phosphine oxides were generated with excellent to good yields (up to 99\%) and high \\ enantioselectivities (up to $98.5: 1.5$ e.r.). The reaction was further investigated by the linear free \\ energy relationship (LFER) analysis. A possible transition state was proposed and furthered verified by \\ theoretical calculations.
}

\section{Introduction}

P-stereogenic compounds, in which the chirality is on the phosphorus atom, have been widely used as biologically active compounds, ${ }^{1}$ chiral ligands ${ }^{2}$ and useful building blocks. ${ }^{3}$ The significance of this privileged structural motif with P-stereogenic centers has led to a great demand for efficient synthetic methods. However, the methodologies used to synthesize such chiral structures were largely limited. ${ }^{4}$ Early reports on P-stereogenic center synthesis comprise the resolution of diastereoisomers, ${ }^{5}$ chiral auxiliary controlled asymmetric reactions, ${ }^{6}$ transition-metal-catalyzed enantioselective cross-coupling, ${ }^{7}$ asymmetric addition reactions of phosphorus nucleophiles, ${ }^{8}$ and desymmetrization of prochiral phosphorus derivatives (Scheme 1a). ${ }^{9}$ Among the above mentioned synthetic strategies of P-stereogenic centers, only two cases were achieved through organocatalysis. ${ }^{10}$ Therefore, it is currently desirable and challenging to develop an organocatalysisbased synthetic methodology for P-stereogenic centers, and to expand the facile and extensive substrate adaptability.

Lewis base catalyzed asymmetric allylic alkylation (AAA) reaction with Morita-Baylis-Hillman (MBH) carbonates as electrophile precursors has been considered as one of the most attractive approaches to build stereogenic centers. However, the AAA strategy currently is restricted to the building of chiral carbon centers, because most frequently used allylation reagents are racemic $\mathrm{MBH}$ adducts. ${ }^{11}$ In fact, it is possible to expand the usage of the AAA strategy to building other noncarbon center chirality when the reactions proceed between achiral MBH adducts and $\mathrm{N}$ (O or S) type nucleophiles. Our

State Key Laboratory of Elemento-Organic Chemistry, College of Chemistry, Nankai University, Tianjin 300071, China. E-mail: xin_li@nankai.edu.cn

$\dagger$ Electronic supplementary information (ESI) available: Experimental procedures, characterization data and computational details. CCDC 1579041. For ESI and crystallographic data in CIF or other electronic format see DOI: 10.1039/c8sc05439h group recently developed a general and efficient method for atroposelective construction of axially chiral anilides (Scheme 1b)..$^{12}$

In continuation of our ongoing interest in the AAA strategy, we speculated that the privileged phosphorus compounds with P-stereogenic centers could be generated via the AAA reaction between bis(2-hydroxyphenyl)phosphinates and achiral MBH carbonates (Scheme 1b). Thus, two challenges need to be solved in this scenario: (i) the difficulty in controlling stereoselectivities due to the lack of chirality at the bonding site; (ii) the difficulty in designing a proper chiral catalyst to induce enantiocontrol during the course of desymmetrization, because the targeted phosphorus center is remote from the enantiotopic site. Herein, we report a biscinchona alkaloid-catalyzed enantioselective desymmetrization of bis(2-hydroxyphenyl)phosphine oxides. Utilizing the AAA strategy based method, a number of phosphine oxides possessing chiral phosphorus(v) atoms were synthesized with good enantioselectivities.

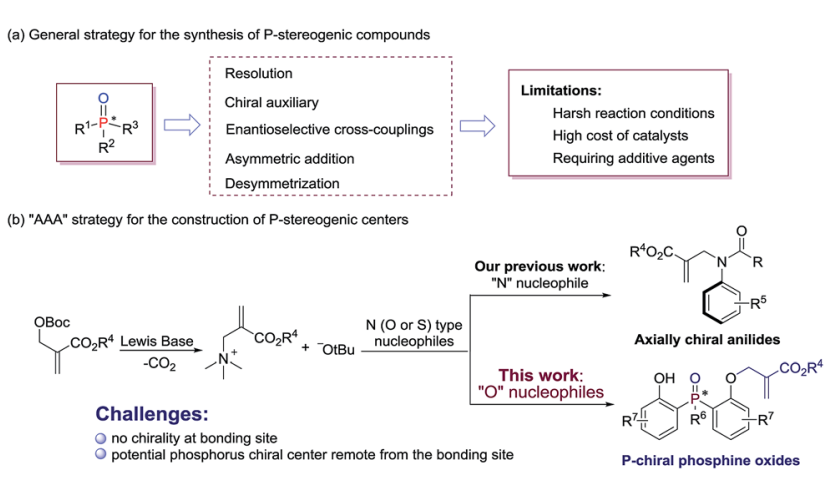

Scheme 1 (a) Methods for the synthesis of P-stereogenic compounds and (b) our design. 


\section{Results and discussion}

\section{Reaction optimization}

Our initial investigation was carried out with bis(2hydroxyphenyl)phosphinate 1a and Boc protected $\mathrm{MBH}$ product 2a as the model substrates, $10 \mathrm{~mol} \%$ of cinchona alkaloid $4 \mathbf{a}$ as the catalyst in $\mathrm{CH}_{2} \mathrm{Cl}_{2}$ at room temperature. The reaction gave the desymmetrization product 3a in $96 \%$ yield, albeit with a racemic result (Table 1, entry 1). To improve the enantioselectivity, we next evaluated different types of cinchona alkaloid catalysts. As shown in Table 1, the catalysts' backbone demonstrated remarkable impacts towards the outcome of the reaction (Table 1, entries 2-8), in which biscinchona alkaloid catalyst $\mathbf{4 f}$ gave the best 66 : 34 e.r (Table 1, entry 6). To further improve the enantioselectivity, we then screened different bisphenol substrates. To our delight, substrates 1b-1d, which had large sized ester groups, showed improved enantioselectivities (Table 1, entries 9-11).

Table 1 Reaction optimization ${ }^{a}$
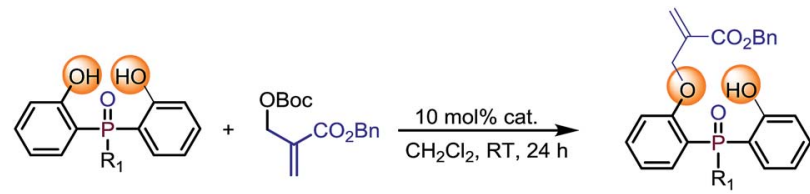

1

$2 \mathbf{a}$

3

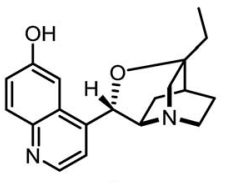

$4 a$

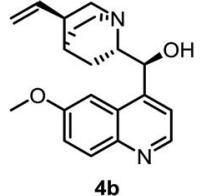

$4 b$ 4c: $(\mathrm{DHQD}){ }_{2} \mathrm{PHAL}$

4d: $(\mathrm{DHQD})_{2} \mathrm{AQN}$

4e: (DHQD) ${ }_{2} P Y R$

4f: $(\mathrm{DHQ})_{2} \mathrm{PHAL}$

4g: $(\mathrm{DHQ})_{2} \mathrm{AQN}$

4h: $(\mathrm{DHQ})_{2} \mathrm{PYR}$

\begin{tabular}{|c|c|c|c|c|c|}
\hline Entry & $R_{1}$ & Cat. & Solvent & Yield $^{b}(\%)$ & e.r. ${ }^{c}$ \\
\hline 1 & 1a: OMe & $4 a$ & $\mathrm{CH}_{2} \mathrm{Cl}_{2}$ & 3a: 96 & $50: 50$ \\
\hline 2 & 1a: OMe & $4 b$ & $\mathrm{CH}_{2} \mathrm{Cl}_{2}$ & 3a: 99 & $54.5: 45.5$ \\
\hline 3 & 1a: OMe & $4 c$ & $\mathrm{CH}_{2} \mathrm{Cl}_{2}$ & 3a: 60 & $51.5: 48.5$ \\
\hline 4 & 1a: OMe & $4 d$ & $\mathrm{CH}_{2} \mathrm{Cl}_{2}$ & 3a: 60 & $52: 48$ \\
\hline 5 & 1a: OMe & $4 e$ & $\mathrm{CH}_{2} \mathrm{Cl}_{2}$ & 3a: 73 & $53.5: 46.5$ \\
\hline 6 & 1a: OMe & 4f & $\mathrm{CH}_{2} \mathrm{Cl}_{2}$ & 3a: 73 & $66: 34$ \\
\hline 7 & 1a: OMe & $4 g$ & $\mathrm{CH}_{2} \mathrm{Cl}_{2}$ & 3a: 68 & $53: 47$ \\
\hline 8 & 1a: OMe & $4 h$ & $\mathrm{CH}_{2} \mathrm{Cl}_{2}$ & 3a: 68 & $53.5: 46.5$ \\
\hline 9 & 1b: OEt & $4 f$ & $\mathrm{CH}_{2} \mathrm{Cl}_{2}$ & 3b: 65 & $68.5: 31.5$ \\
\hline 10 & 1c: $\mathrm{O} i \mathrm{Pr}$ & $4 f$ & $\mathrm{CH}_{2} \mathrm{Cl}_{2}$ & 3c: 64 & $70.5: 31.5$ \\
\hline 11 & 1d: OAd & $4 f$ & $\mathrm{CH}_{2} \mathrm{Cl}_{2}$ & 3d: 90 & $71.5: 28.5$ \\
\hline 12 & 1e: Ad & 4f & $\mathrm{CH}_{2} \mathrm{Cl}_{2}$ & 3e: 90 & $84: 16$ \\
\hline $13^{d}$ & 1e: Ad & $4 f$ & $\mathrm{CH}_{2} \mathrm{Cl}_{2}$ & 3e: 46 & $94: 6$ \\
\hline $14^{d}$ & 1e: Ad & $4 f$ & $\mathrm{CHCl}_{3}$ & 3e: 60 & $94.5: 5.5$ \\
\hline $15^{d}$ & 1e: Ad & 4f & THF & 3e: 36 & $94: 6$ \\
\hline $16^{d}$ & 1e: Ad & 4f & Toluene & Trace & $\mathrm{Nd}^{f}$ \\
\hline $17^{d}$ & 1e: Ad & 4f & Ether & Trace & $\mathrm{Nd}^{f}$ \\
\hline $18^{d, e}$ & 1e: Ad & 4f & $\mathrm{CHCl}_{3}$ & 3e: 84 & $94.5: 5.5$ \\
\hline
\end{tabular}

${ }^{a}$ Reaction conditions: phosphinate $\mathbf{1}(0.1 \mathrm{mmol}), \mathrm{MBH}$ carbonate $2 \mathrm{a}$ $(0.12 \mathrm{mmol})$, catalyst $(10 \mathrm{~mol} \%)$, in $1 \mathrm{~mL}$ of solvent. ${ }^{b}$ Isolated yields. ${ }^{c}$ Determined by chiral HPLC analysis. ${ }^{d}$ The reaction was conducted at $-40{ }^{\circ} \mathrm{C}$ with $20 \mathrm{~mol} \%$ (DHQ) $)_{2}$ PHAL and the reaction time was 6 days. ${ }^{e}$ With 0.2 mmol $2 a .{ }^{f}$ Not determined.
This result indicated that the enantioselectivity of the studied desymmetrization reaction may be closely related to the steric hindrance of the substituent linked to the pre-stereogenic Pcenter. This hypothesis was furthermore supported by the reaction with substrate phosphine oxide 1e, in which the enantioselectivity was obtained as 84 : 16 e.r (Table 1, entry 12). A series of subsequent screenings (for example, temperature, solvent, and substrate ratio) showed enhancement of the enantioselectivity. Lowering the reaction temperature to $-40{ }^{\circ} \mathrm{C}$ can further increase the e.r. value to $94: 6$, while increasing the catalyst loading and prolonging the reaction time were necessary to ensure the conversion of the reaction (Table 1 , entry 13). The evaluation of the solvents showed that $\mathrm{CHCl}_{3}$ was the best reaction medium in terms of reactivity and enantioselectivity (Table 1, entries 13-17). Increasing amount of substrate $2 \mathrm{a}$ obtained an improved yield of $84 \%$ with retention of $94.5: 5.5$ e.r (Table 1 , entry 18 ).

\section{Substrate evaluation}

With the optimal reaction conditions in hand, we set out to explore the substrate generality of this desymmetrization strategy. Firstly, different substituted phosphine oxides were investigated. As shown in Table 2, substrates with electron-donating groups and electron-withdrawing groups on the phenyl ring were well tolerated in this reaction. The corresponding products $\mathbf{3 e - 3 k}$ and 3m-3o were afforded in 34-91\% yields and 91.0 : 9.0-98.5 : 1.5 e.r. values. When the substituted atom was $\mathrm{F}$, the enantioselectivity decreased to a moderate level (31, 65\% yield and

Table 2 Substrate scope of phosphine oxide substrates ${ }^{a}$

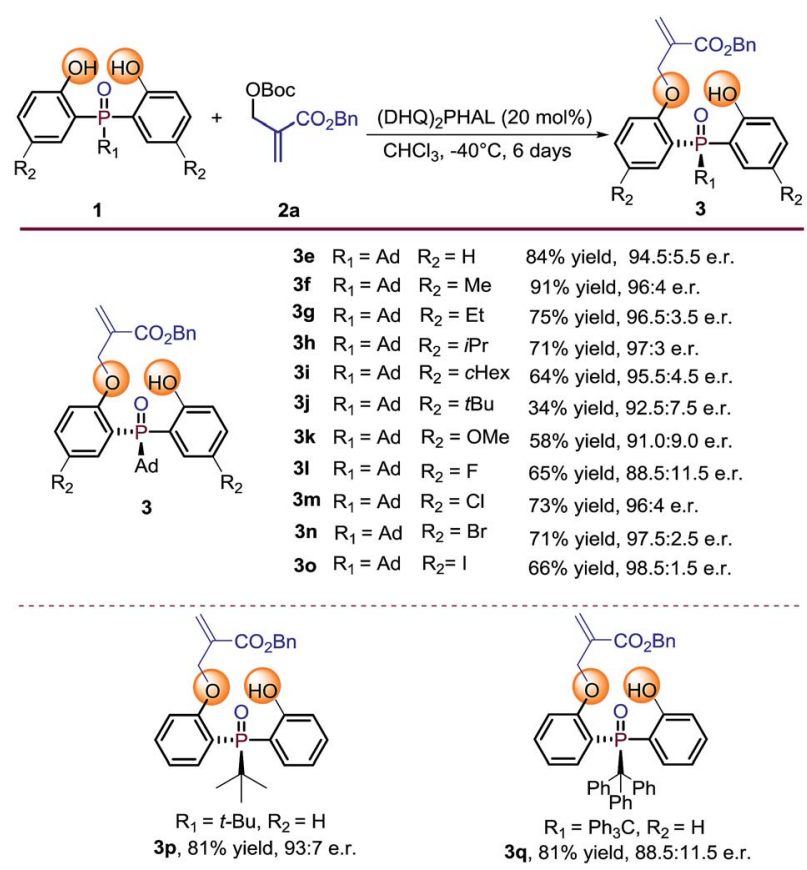

${ }^{a}$ Reaction conditions: phosphine oxides $1(0.1 \mathrm{mmol}), \mathrm{MBH}$ carbonate 2a $(0.2 \mathrm{mmol})$, catalyst $(20 \mathrm{~mol} \%), 1 \mathrm{~mL} \mathrm{CHCl}_{3}$. Isolated yields. e.r. values were determined by chiral HPLC analysis. 
88.5 : 11.5 e.r.). It is valuable to note that the steric hindrance of the substituent seems to also influence on the reactivity. For example, the substrate with $\mathrm{R}_{2}$ as the tert-butyl group only provided the corresponding product $3 \mathbf{j}$ with $34 \%$ yield under the optimized reaction conditions. Two other substrates with large steric hindrance phosphine oxides, in which the groups linked to the P-center were tert-butyl and triphenyl methyl, were also examined. As a result, 3p was obtained in $81 \%$ yield with $93: 7$ e.r. and $3 q$ was obtained in $81 \%$ yield with 88.5 : 11.5 e.r.

Further investigation of the substrate scope was focused on the Boc protected $\mathrm{MBH}$ carbonate substrates 2 (Table 3). The electronic nature or position of the substituent on the benzyl ring does not appear to affect the results, all the benzylsubstituted $\mathrm{MBH}$ carbonates afforded the target products 3t$3 \mathrm{e}^{\prime}$ in moderate to excellent yields (41-99\%) with excellent enantioselectivities (95.5: 4.5 to $97.5: 2.5$ e.r.). The 1-methylnaphthyl type $\mathrm{MBH}$ carbonate tolerated well under the optimal condition, gave $3 \mathrm{~s}$ in $93 \%$ yield with 95.5 : 4.5 e.r. The tert-butyl substituted $\mathrm{MBH}$ carbonate is also transformed to the desired product $3 \mathrm{r}$ in $61 \%$ yield and $92: 8$ e.r. by running the reaction at $0{ }^{\circ} \mathrm{C}$ albeit with large steric hindrance. The absolute configuration of 3r was determined by X-ray diffraction analysis and those of other products were assigned by analogy. ${ }^{13}$

\section{LFER research studies}

The substrate scope study reveals that, in general, products with large sized substituents on the aromatic ring of phosphine have

Table 3 Substrate scope of MBH carbonate substrates ${ }^{a}$
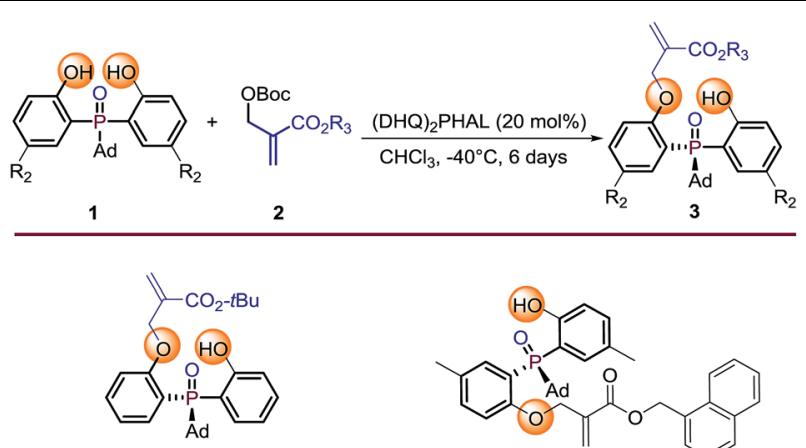

$\mathrm{R}_{2}=\mathrm{H}, \mathrm{R}_{3}=t-\mathrm{Bu}$

$3 \mathbf{r}^{b}, 61 \%$ yield, $92: 8$ e.r.

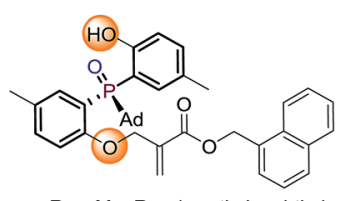

$R_{2}=M e, R_{3}=1$-methylnaphthyl

3s, $93 \%$ yield, 95.5:4.5 e.r.

3t, $\mathrm{R}^{2}=\mathrm{Me}, \mathrm{G}=2-\mathrm{CF}_{3}, 99 \%$ yield, $96: 4$ e.r. $3 \mathrm{u}, \mathrm{R}^{2}=\mathrm{Me}, \mathrm{G}=2-\mathrm{Me}, 77 \%$ yield, 95.5:4.5 e.r. $3 v, R^{2}=\mathrm{Me}, \mathrm{G}=2-\mathrm{MeO}, 46 \%$ yield, 96.5:3.5 e.r. $3 w, R^{2}=M e, G=2-C l, 99 \%$ yield, 95.5:4.5 e.r. $3 x, R^{2}=M e, G=3-M e, 75 \%$ yield, $95: 5$ e.r. $3 y, R^{2}=M e, G=3-M e O, 78 \%$ yield, $95: 5$ e.r. 3z, $\mathrm{R}^{2}=\mathrm{Me}, \mathrm{G}=3-\mathrm{Cl}, 88 \%$ yield, $96: 4$ e.r. 3a', $R^{2}=M e, G=4-F, 85 \%$ yield, $96: 4$ e.r. $3 \mathbf{b}^{\prime}, \mathrm{R}^{2}=\mathrm{Me}, \mathrm{G}=4-\mathrm{Cl}, 99 \%$ yield, $96: 4$ e.r. $3 c^{\prime}, R^{2}=B r, G=2-M e, 52 \%$ yield, 96.5:3.5 e.r. 3d', $R^{2}=\mathrm{Br}, \mathrm{G}=3 \mathrm{MeO}, 41 \%$ yield, 97.5:2.5 e.r. $3 e^{\prime}, R^{2}=B r, G=4-F, 70 \%$ yield, $97: 3$ e.r.

${ }^{a}$ Reaction conditions: phosphine oxides 1 ( $\left.0.1 \mathrm{mmol}\right), \mathrm{MBH}$ carbonates $2(0.2 \mathrm{mmol})$, catalyst $(20 \mathrm{~mol} \%), 1 \mathrm{~mL} \mathrm{CHCl}_{3}$. Isolated yields. e.r. values were determined by chiral HPLC analysis. ${ }^{b}$ The reaction was conducted at $0{ }^{\circ} \mathrm{C}$. better enantioselectivity. To investigate the effect of the steric factor on the enantioselectivity, we plotted the enantioselectivities against Charton values. ${ }^{\mathbf{1 4}}$ Preliminary analysis revealed that substrates having large steric substituents $\mathrm{R}_{2}$ gave better enantioselectivities (For $\mathrm{R}_{2}=\mathrm{H}, \mathrm{Me}, \mathrm{Et}, i \mathrm{Pr}$, see Fig. S1 in the ESI $\dagger$ ). This rule could also be expanded to substrates containing halogen substituents $\left(\mathrm{R}_{2}=\mathrm{F}, \mathrm{Cl}, \mathrm{Br}\right.$, I, see Fig. S2 in the ESI $\left.\dagger\right)$. It seemed that the steric factor may play a role in enantioselectivity control. However, the steric correlation could not explain the stereoselectivity for the substrates containing other large
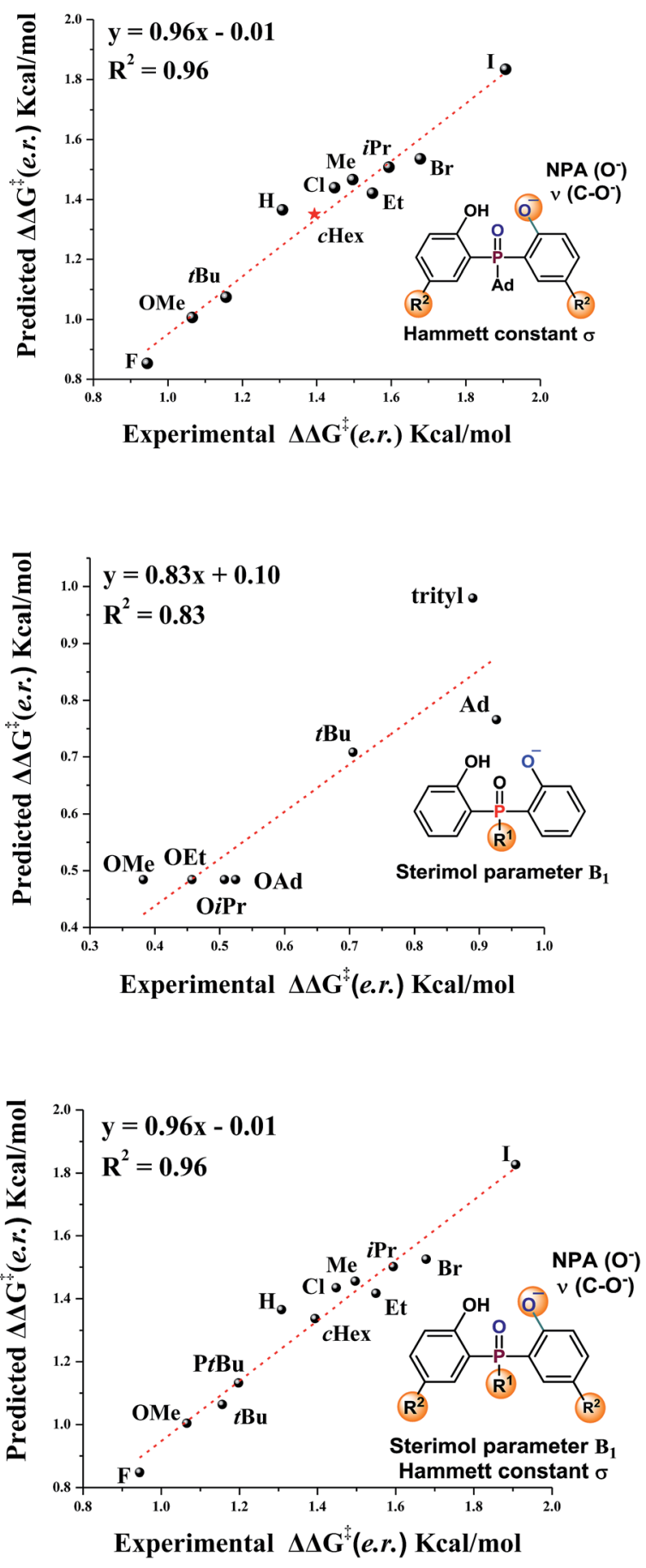

Fig. 1 Correlation of enantioselectivity with substrate parameters. 
hindrance substituents, such as $\mathrm{R}_{2}=t \mathrm{Bu}$ or $c$ Hex. Thus, other factors, such as the electronic effect, should also be considered.

Recently, Sigman and coworkers utilized multivariate linear regression (MLR) models to effectively predict the experimental reaction outcome based on both experimentally derived and calculated physical organic molecular descriptors. ${ }^{15}$ Inspired by their work and our previous related study, ${ }^{12}$ we explored the factors that govern the stereoselectivity. The regression analysis was made with ten data sets and tested with one data set. After evaluating various parameters, the Hammett constant $(\sigma)$, NPA charge $\left(\mathrm{O}^{-}\right)$and $\nu\left(\mathrm{C}-\mathrm{O}^{-}\right),{ }^{15 b, c}$ which can be used to embody the steric and electronic effects, were found to accurately predict the stereoselectivity (eqn (1), Fig. 1, slope $=0.96$, intercept $=-0.01$, $\left.R^{2}=0.96\right)$. Besides, the effects of substituents linked to the prestereogenic P-center were evaluated. The stereoselectivity is in good correlation with Sterimol parameter $B_{1}$ (eqn (2)). ${ }^{16}$ The steric factor of substituents linked to the phosphorus atom significantly affected the enantioselectivity. Finally, based on eqn (2), eqn (1) could be expanded to substrates that have different substituents linked to the pre-stereogenic P-center (eqn (3), slope $=0.96$, intercept $=-0.01, R^{2}=0.96$ ).

$$
\begin{gathered}
\Delta \Delta G^{\ddagger}(\text { e.r. })=-3.04 \sigma+78.6 \mathrm{NPA}_{\left(\mathrm{O}^{-}\right)}-0.014 \nu_{\left(\mathrm{C}-\mathrm{O}^{-}\right)}+88.2 \\
\Delta \Delta G^{\ddagger}(\text { e.r. })=0.16 B_{1}+0.24 \\
\Delta \Delta G^{\ddagger}(\text { e.r. })=-3.03 \sigma+78.1 \mathrm{NPA}_{\left(\mathrm{O}^{-}\right)}-0.0144 \nu_{\left({\left.\mathrm{C}-\mathrm{O}^{-}\right)}\right.} \\
+0.828 B_{1}+85.7
\end{gathered}
$$

\section{Theoretical calculations}

Theoretical calculations were conducted to support the above analysis. ${ }^{17,18}$ Extensive explorations of a variety of catalytic arrangements show that the two most stable transition state structures are TS1 and TS2 (Fig. 2). The free energy difference between TS1 and TS2 is $2.2 \mathrm{kcal} \mathrm{mol}^{-1}$, which agrees with experimental data, 85 : 15 e.r. As shown in Fig. 2, TS1 is stabilized by a $\mathrm{C}-\mathrm{H} \cdots \pi$ interaction between the methylene of the quinuclidine ring and the aromatic ring of phenol. However, this interaction is missing in TS2, which would be a key factor that contributes to the energy difference between TS1 and TS2. Previous studies of $\mathrm{C}-\mathrm{H} \cdots \pi$ interactions showed that the interaction energies correlated with Hammett constant $\left(\sigma_{\mathrm{m}}\right),{ }^{19}$ which supported our LFER analysis. The steric factor of substituents linked to the pre-stereogenic P-center could also be explained by transition states. If the tert-butyl group linked to the phosphorus atom is replaced by an adamantyl group, the steric effect between the catalyst and substrate will destabilize TS2, which is crucial for excellent enantioselectivity control.

\section{Large scale reaction and product transformation}

To probe the efficiency of the current studied desymmetrization strategy in preparative synthesis, large scale reactions were investigated under the optimal conditions. To our delight, the desired products $3 \mathbf{e}$ and $3 \mathbf{f}$ were obtained without any loss of enantioselectivity (Scheme 2). Further bromination of $3 \mathbf{f}$ by 1.5 equiv. NBS afforded $\mathbf{4 b}$. Treating $\mathbf{4 b}$ with 5 equivalents of DMAP afforded $\mathbf{5 b}$ in moderate yield with retention of
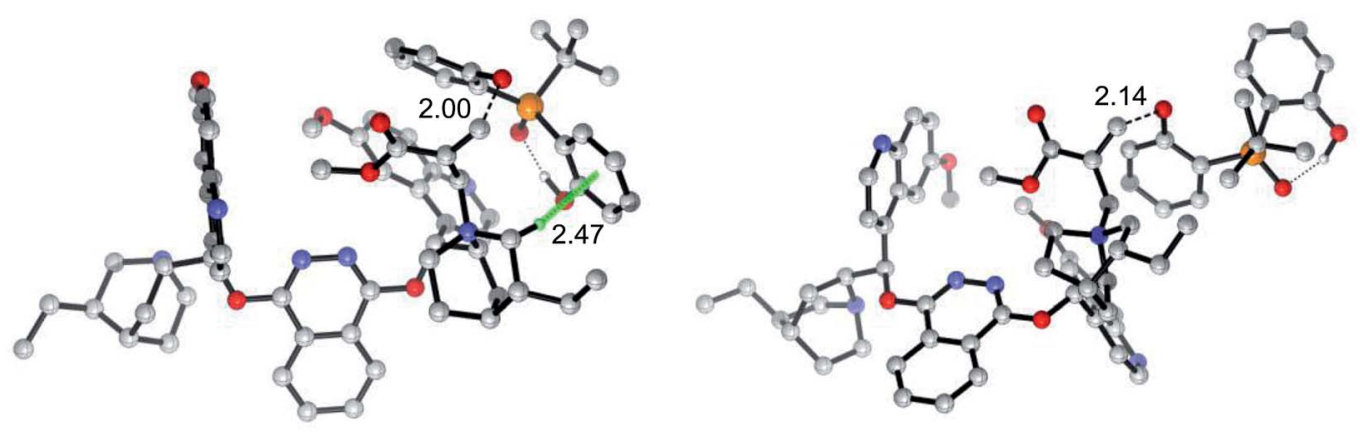

TS1

$\Delta \Delta \mathbf{G}^{*}=\mathbf{0 . 0}$

TS2
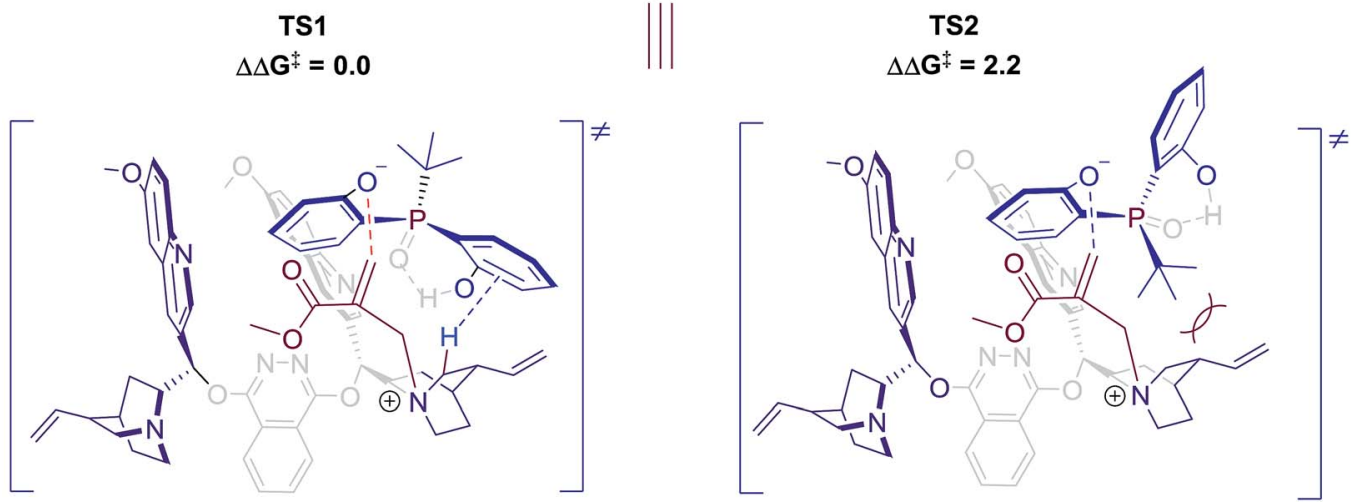

Fig. 2 Transition state structures and relative free energies (in $\mathrm{kcal} \mathrm{mol}^{-1}$ ) for desymmetrization catalyzed by $4 \mathrm{f}$. Noncritical hydrogen atoms have been omitted for clarity. The $\mathrm{C}-\mathrm{H} \cdots \pi$ interaction in TS1 is highlighted. 

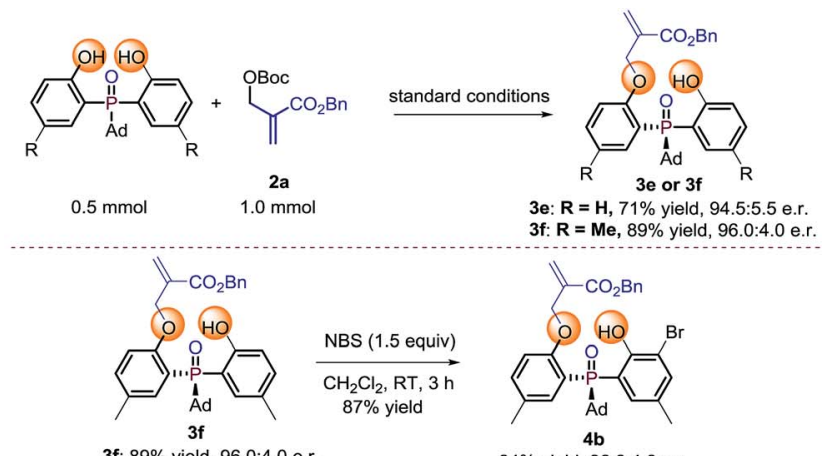

3f: $\mathbf{R}=$ Me, $89 \%$ yield, 96.0:4.0 e.r.

3f: $89 \%$ yield, $96.0: 4.0$ e.r.

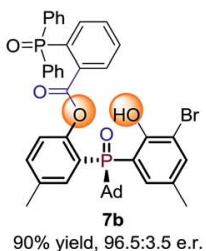

$90 \%$ yield, $96.5: 3.5$ e.r.
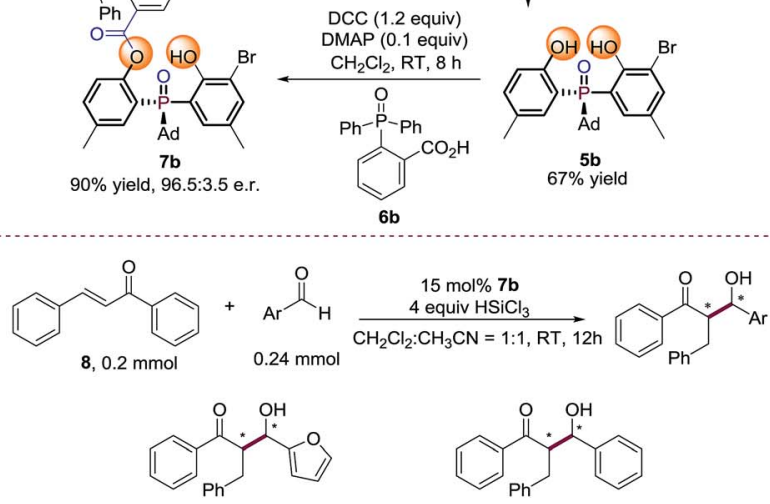

9. $63 \%$ yield $75.25 \mathrm{dr}$ 51.0:49.0 e.r./62.5:37.5 e.r.

$10,59 \%$ yield, $53: 47 \mathrm{dr}$, 53.0:47.0 e.r. $/ 55.5: 45.5$ e.r.

Scheme 2 Large scale reaction and synthetic transformations of the product. $^{21}$

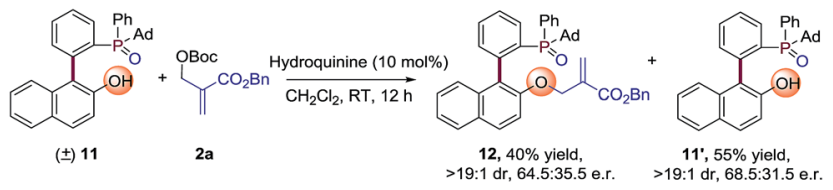

Scheme 3 Kinetic resolution experiment using the AAA strategy.

enantioselectivity. Finally, product $7 \mathbf{b}$ can be obtained in $90 \%$ yield with 96.5 : 3.5 e.r. under the conditions shown in Scheme 2. The preliminary application of the synthesized bidentate chiral phosphine oxide indicated that $\mathbf{7 b}$ could be used as a catalyst in asymmetric reactions between enones and aldehydes (Scheme 2). ${ }^{20}$

Moreover, we also made another kinetic resolution experiment with substrate $( \pm)$-11, which contains both axial and phosphorus prochirality (Scheme 3 ). The reaction of $( \pm)-\mathbf{1 1}$ with 2 a proceeds smoothly in the presence of $10 \mathrm{~mol} \%$ hydroquinine under the standard conditions, resulting in $\mathbf{1 2}$ in $40 \%$ yield with $64.5: 35.5$ e.r. and 11' in $55 \%$ yield with 68.5 : 31.5 e.r. Further optimization of reaction conditions may lead to better enantioselectivities. This result again proves the universality of the strategy for the synthesis of P-stereogenic compounds.

\section{Conclusions}

In summary, we have developed a catalytic enantioselective desymmetrization of bisphenols that hold pre-stereogenic Pcenters, using a biscinchona alkaloid catalyst. This AAA strategy based method provides a novel and highly efficient way to the synthesis of P-stereogenic compounds, affording the desired functionalized phosphine oxides in good yields (up to $99 \%$ ) and high enantioselectivities (up to $98.5: 1.5$ e.r.). A range of functional groups were tolerated under the mild reaction conditions. A possible transition state was proposed based on the linear free energy relationship analysis, which was further verified by theoretical calculations.

\section{Conflicts of interest}

There are no conflicts to declare.

\section{Acknowledgements}

We are grateful to the NNSFC (grant no. 21390400) for financial support.

\section{Notes and references}

1 (a) The Role of Phosphonates in Living Systemsk, ed. R. L. Hildebrand, CRC Press, Boca Raton, Fla, 1983; (b) G. Lavielle, P. Hautefaye, C. Schaeffer, J. A. Boutin, C. A. Cudennec and A. Pierre, J. Med. Chem., 1991, 34, 1998; (c) F. R. Atherton, C. H. Hassall and R. W. Lambert, J. Med. Chem., 1986, 29, 29; (d) K. Lin, S. Zhou, C. Xu and W. P. Liu, J. Agric. Food Chem., 2006, 54, 8134.

2 (a) Phosphorus Ligands in Asymmetric: Catalysis synthesis and applications, ed. A. Borner, Wiley-VCH, Weinheim, 2008; (b) Phosphorus (III) Ligands in Homogeneous Catalysis: Design and Synthesis, ed. P. C. J. Kamer and P. W. N. M. van Leeuwen, Wiley: Chichester, U.K., 2012. p. 3029; (c) W. Tang and X. Zhang, Chem. Rev., 2003, 103, 3029; (d) J. H. Xie and Q. L. Zhou, Acc. Chem. Res., 2008, 41, 581.

3 (a) X. Lu, C. Zhang and Z. Xu, Acc. Chem. Res., 2001, 34, 535; (b) S. E. Denmark and J. Fu, Chem. Rev., 2003, 103, 2763; (c) J. L. Methot and W. R. Roush, Adv. Synth. Catal., 2004, 346, 1035; (d) B. J. Cowen and S. J. Miller, Chem. Soc. Rev., 2009, 38, 3102; (e) Y. Wei and M. Shi, Acc. Chem. Res., 2010, 43, 1005; (f) M. Sampath and T. P. Loh, Chem. Sci., 2010, 1, 739; $(g)$ A. Marinetti and A. Voituriez, Synlett, 2010, 174; $(h)$ Q. Y. Zhao, Z. Lian, Y. Wei and M. Shi, Chem. Commun., 2012, 48, 1724; (i) C. E. Henry, Q. Xu, Y. C. Fan, T. J. Martin, L. Belding, T. Dudding and O. Kwon, J. Am. Chem. Soc., 2014, 136, 11890; (j) Z. Wang, X. Xu and O. Kwon, Chem. Soc. Rev., 2014, 43, 2927; (k) M. Gicquel, Y. Zhang, P. Aillard, P. Retailleau, A. Voituriez and A. Marinetti, Angew. Chem., Int. Ed., 2015, 54, 5470.

4 (a) O. I. Kolodiazhnyi, Tetrahedron: Asymmetry, 2012, 23, 1; (b) L. A. Wozniak and A. Okruszek, Chem. Soc. Rev., 2003, 32, 158; (c) H. Fernández-Pérez, P. Etayo, A. Panossian and A. Vidal-Ferran, Chem. Rev., 2011, 111, 2119; (d) 
M. Dutartre, J. Bayardon and S. Jugé, Chem. Soc. Rev., 2016, 45, 5771 .

5 (a) S. B. Wild, Coord. Chem. Rev., 1997, 166, 291; (b) D. S. Glueck, Chem.-Eur. J., 2008, 14, 7108; (c) V. S. Chan, M. Chiu, R. G. Bergman and F. D. Toste, J. Am. Chem. Soc., 2009, 131, 6021; (d) J. S. Harvey and V. Gouverneur, Chem. Commun., 2010, 46, 7477; (e) F. A. Kortmann, M. C. Chang, E. Otten, E. P. A. Couzijn, M. Lutz and A. J. Minnaard, Chem. Sci., 2014, 5, 1322.

6 (a) E. Bergin, C. T. O'Connor, S. B. Robinson, E. M. McGarrigle, C. P. O'Mahony and D. G. Gilheany, J. Am. Chem. Soc., 2007, 129, 9566; (b) D. Gatineau, L. Giordano and G. Buono, J. Am. Chem. Soc., 2011, 133, 10728; (c) Z. S. Han, N. Goyal, M. A. Herbage, J. D. Sieber, B. Qu, Y. Xu, Z. Li, J. T. Reeves, J. N. Desrosiers, S. Ma, N. Grinberg, H. Lee, H. P. R. Mangunuru, Y. Zhang, D. Krishnamurthy, B. Z. Lu, J. J. Song, G. Wang and C. H. Senanayake, J. Am. Chem. Soc., 2013, 135, 2474; (d) O. Berger and J. L. Montchamp, Angew. Chem., Int. Ed., 2013, 52, 11377; (e) S. Rast, B. Mohar and M. Stephan, Org. Lett., 2014, 16, 2688; (f) K. Nikitin, K. V. Rajendran, H. Müller-Bunz and D. G. Gilheany, Angew. Chem., Int. Ed., 2014, 53, 1906; $(g)$ J. D. Sieber, D. Chennamadhavuni, K. R. Fandrick, B. Qu, Z. S. Han, J. Savoie, S. Ma, L. P. Samankumara, N. Grinberg, H. Lee, J. J. Song and C. H. Senanayake, Org. Lett., 2014, 16, 5494.

7 (a) R. M. Alexander, R. C. Kevin and A. E. David, J. Am. Chem. Soc., 1995, 117, 9075; (b) G. Cédric, S. J. Canipa, P. O'Brien and S. Taylor, J. Am. Chem. Soc., 2006, 128, 9336; (c) C. Scriban and D. S. Glueck, J. Am. Chem. Soc., 2006, 128, 2788; (d) V. S. Chan, I. C. Stewart, R. G. Bergman and F. D. Toste, J. Am. Chem. Soc., 2006, 128, 2786; (e) Z. Q. Lin, W. Z. Wang, S. B. Yan and W. L. Duan, Angew. Chem., Int. Ed., 2015, 54, 6265; (f) R. Beaud, R. J. Phipps and M. J. Gaunt, J. Am. Chem. Soc., 2016, 138, 13183; $(g)$ B. Pérez-Saavedra, N. Vázquez-Galiñanes, C. Saá and M. Fañanás-Mastral, ACS Catal., 2017, 7, 6104; (h) Y. S. Jang, Ł. Woźniak, J. Pedroni and N. Cramer, Angew. Chem., Int. Ed., 2018, 57, 12901.

8 (a) C. Scriban, I. Kovacik and D. S. Glueck, Organometallics, 2005, 24, 4871; (b) D. P. Zhao and R. Wang, Chem. Soc. Rev., 2012, 41, 2095; (c) Y. Huang, Y. Li, P. Leung and T. Hayashi, J. Am. Chem. Soc., 2014, 136, 4865; (d) C. Li, Q. Bian, S. Xu and W. Duan, Org. Chem. Front., 2014, 1, 541.

9 (a) D. Wiktelius, M. J. Johansson, K. Luthman and N. Kann, Org. Lett., 2005, 7, 4991; (b) J. S. Harvey, S. J. Malcolmson, K. S. Dunne, S. J. Meek, A. L. Thompson, R. R. Schrock, A. H. Hoveyda and V. Gouverneur, Angew. Chem., Int. Ed., 2009, 48, 762; (c) Z. J. Du, J. Guan, G. J. Wu, P. Xu, L. X. Gao and F. S. Han, J. Am. Chem. Soc., 2015, 137, 632; (d) Y. S. Jang, M. Dieckmann and N. Cramer, Angew. Chem., Int. Ed., 2017, 56, 15088; (e) Y. Zheng, L. N. Guo and W. W. Zi, Org. Lett., 2018, 20, 7039.

10 (a) Z. J. Huang, X. Huang, B. S. Li, C. L. Mou, S. Yang, B. A. Song and Y. G. Robin Chi, J. Am. Chem. Soc., 2016, 138, 7524; (b) Y. Toda, M. Pink and J. N. Johnston, J. Am. Chem. Soc., 2014, 136, 14734.
11 (a) O. Belda and C. Moberg, Acc. Chem. Res., 2004, 37, 159; (b) B. M. Trost, M. R. Machacek and A. Aponick, Acc. Chem. Res., 2006, 39, 747; (c) C. W. Cho and M. J. Krische, Angew. Chem., Int. Ed., 2004, 43, 6689; (d) Y. Q. Jiang, Y. L. Shi and M. Shi, J. Am. Chem. Soc., 2008, 130, 7202; (e) H. L. Cui, X. Feng, J. Peng, J. Lei, K. Jiang and Y. C. Chen, Angew. Chem., Int. Ed., 2009, 48, 5737; $(f)$ X. Wang, F. Meng, Y. Wang, Z. Han, Y. J. Chen, L. Liu, Z. Wang and K. Ding, Angew. Chem., Int. Ed., 2012, 51, 9276; (g) X. Wang, P. Guo, Z. Han, X. Wang, Z. Wang and K. Ding, J. Am. Chem. Soc., 2014, 136, 405.

12 S. L. Li, C. Yang, Q. Wu, H. L. Zheng, X. Li and J. P. Cheng, J. Am. Chem. Soc., 2018, 140, 12836.

13 CCDC: 1579041 , see $\mathrm{ESI} \dagger$ for more details.

14 (a) M. Charton, J. Am. Chem. Soc., 1969, 91, 615; (b) M. Charton, J. Am. Chem. Soc., 1975, 97, 1552; (c) M. Charton, J. Am. Chem. Soc., 1975, 97, 3691; (d) M. Charton, J. Am. Chem. Soc., 1975, 97, 3694.

15 (a) For selected review: M. S. Sigman, K. C. Harper, E. N. Bess and A. Milo, Acc. Chem. Res., 2016, 49, 1292; (b) C. B. Santiago, J. Y. Guo and M. S. Sigman, Chem. Sci., 2018, 9, 2398. For selected examples:(c) A. Milo, E. N. Bess and M. S. Sigman, Nature, 2014, 507, 210; (d) C. Zhang, C. B. Santiago, L. Kou and M. S. Sigman, J. Am. Chem. Soc., 2015, 137, 7290; (e) M. Orlandi, M. J. Hilton, E. Yamamoto, F. D. Toste and M. S. Sigman, J. Am. Chem. Soc., 2017, 139, 12688; (f) R. T. Thornbury, V. Saini, T. d. A. Fernandes, C. B. Santiago, E. P. A. Talbot, M. S. Sigman, J. M. McKenna and F. D. Toste, Chem. Sci., 2017, 8, 2890; (g) J. M. Crawford, E. A. Stone, A. Metrano, S. J. Miller and M. S. Sigman, J. Am. Chem. Soc., 2018, 140, 868; (h) S. B. Zhao, T. Gensch, B. Murray, Z. L. Niemeyer, M. S. Sigman and M. R. Biscoe, Science, 2018, 362, 670; (i) J. A. S. Coelho, A. Matsumoto, M. Orlandi, M. J. Hilton, M. S. Sigman and F. D. Toste, Chem. Sci., 2018, 9, 7153; (j) S. Biswas, K. Kubota, M. Orlandi, M. Turberg, D. H. Miles, M. S. Sigman and F. D. Toste, Angew. Chem., Int. Ed., 2018, 57, 589.

16 (a) A. Verloop, Drug Design, Academic Press, New York, 1976; (b) A. Verloop and J. Tipker, Biological Activity and Chemical Structure, Elsevier, Amsterdam, 1977; (c) A. Verloop, IUPAC Pesticide Chemistry, Pergamon, Oxford, 1983.

17 To reduce the computational cost, a methyl group substituted $\mathrm{MBH}$ substrate and tert-butyl substituted phosphine oxide substrate were used. The experimental e.r. value of the product was $85: 15$, which was obtained under identical conditions.

18 M. J. Frisch, et al., Gaussian 09, revision D.01, Gaussian, Inc., 2013. See ESI† for full citation and calculation details.

19 (a) S. E. Wheeler and K. N. Houk, J. Am. Chem. Soc., 2008, 130, 10854; (b) B. W. Gung, B. U. Emenike, M. Lewis and K. Kirschbaum, Chem.-Eur. J., 2010, 16, 12357; (c) J. W. G. Bloom, R. K. Raju and S. E. Wheeler, J. Chem. Theory Comput., 2012, 8, 3167.

20 (a) M. Sugiura, N. Sato, Y. Sonoda, S. Kotani and M. Nakajima, Chem. - Asian J., 2010, 5, 478; (b) M. Sugiura, N. Sato, S. Kotani and M. Nakajima, Chem. Commun., 2008, 44, 4309.

21 For details of derivatization, see ESI. $\dagger$ 